in vivo $33: 501-506(2019)$

doi:10.21873/invivo.11502

\title{
Post-esophagectomy Adjuvant Chemotherapy Benefits Esophageal Cancer Patients
}

\author{
MAKOTO SOHDA, HIDEYUKI SAITO, KENGO KURIYAMA, TOMONORI YOSHIDA, YUJI KUMAKURA, \\ HIROAKI HONJYO, KEIGO HARA, DAIGO OZAWA, SHIGEMASA SUZUKI, NARITAKA TANAKA, \\ MAKOTO SAKAI, TATSUYA MIYAZAKI, MINORU FUKUCHI and HIROYUKI KUWANO
}

Department of General Surgical Science, Gunma University Graduate School of Medicine, Maebashi, Japan

\begin{abstract}
Background/Aim: Postoperative chemotherapy is an absolutely imperative treatment for advanced esophageal cancer patients, while preoperative chemotherapy is the standard therapy for clinical stage II/III esophageal squamous cell carcinoma (ESCC) in Japan. The aim of this study was to report the effect of postoperative chemotherapy on survival after esophagectomy due to thoracic esophageal squamous cell carcinoma. Patients and Methods: One hundred thirteen consecutive patients with esophageal carcinoma who underwent esophagectomy were included. Several regiments were performed at various times. Results: Adjuvant chemotherapy brought a significantly superior overall survival ( $p=0.002)$, although there was no significant difference in cancer-specific survival $(p=0.054)$ for clinical stage II or stage III esophageal cancer patients. Depth of invasion ( $p=0.003)$, number of lymph node metastases $(p=0.048)$, and venous invasion $(p<0.001)$ were risk factors for recurrence in the adjuvant-chemotherapy group with positive lymph nodes. Additionally, a not well-differentiated type, lymphatic and venous invasions were risk factors for recurrence in the surgery-alone group without positive lymph nodes. Conclusion: Postoperative adjuvant chemotherapy contributes to the prognosis of clinical stage II or III esophageal cancer patients.
\end{abstract}

Esophageal cancer is a common malignant neoplasm. In spite of recent improvements in surgical techniques and

This article is freely accessible online.

Correspondence to: Makoto Sohda, MD, Ph.D., Department of General Surgical Science, Gunma University Graduate School of Medicine, 3-39-22, Showa-machi, Maebashi, Gunma 371-8511, Japan. Tel: +81 272208224, Fax: +81 272208230, e-mail: msohda@gunma-u.ac.jp

Key Words: Esophagectomy, adjuvant chemotherapy, esophageal cancer. adjuvant therapies, the prognosis of patients with advanced disease remains poor $(1,2)$. This is mainly because esophageal cancer commonly spreads aggressively through the lymphatic system. Zhang et al, proposed that the number of lymph node (LN) metastases reflects the prognosis of patients with esophageal cancer (3). They reported that the 5 -year survival rate of patients with two or more metastatic LNs was $9.35 \%$, which was significantly worse than that of patients with one LN or no metastatic LNs. Lin et al., also demonstrated that metastasis to 4 or more LNs was a significant independent prognostic factor of thoracic esophageal squamous cell carcinoma (4). Adjuvant chemotherapy is an absolutely imperative treatment for advanced esophageal cancer patients. The JCOG9204 phase III trial, performed by Ando et al., to compare survival with surgery alone and with postoperative adjuvant chemotherapy with two courses of cisplatin and fluorouracil (FP) in patients with resected esophageal squamous cell carcinoma, concluded that there was a significant five-year disease-free survival (DFS) benefit from postoperative adjuvant chemotherapy with FP in the group of patients with positive lymph nodes (5). However, there was no significant difference in the OS of the two groups (5). These results were consistent with other reports $(6,7)$. Recently, Rong et al. have also reported that the group receiving adjuvant chemotherapy with docetaxel- or paclitaxel-based regimens had significantly longer median DFS than the surgery-alone group; however, there was no significant difference in the OS of these groups (8). The effects of preoperative chemotherapy are being evaluated in randomized trials. Several studies have demonstrated a survival benefit with surgery alone (9-11). The JCOG9907 clinical trial, which compared survival following postoperative adjuvant chemotherapy with FP versus preoperative chemotherapy for localized advanced squamous cell carcinoma of the thoracic esophagus, showed that preoperative chemotherapy brought significantly superior overall survival (10). However, there was no significant difference between groups with respect to progression-free survival. Additionally, there was no 


\section{Details of treatment in total 113 patients}

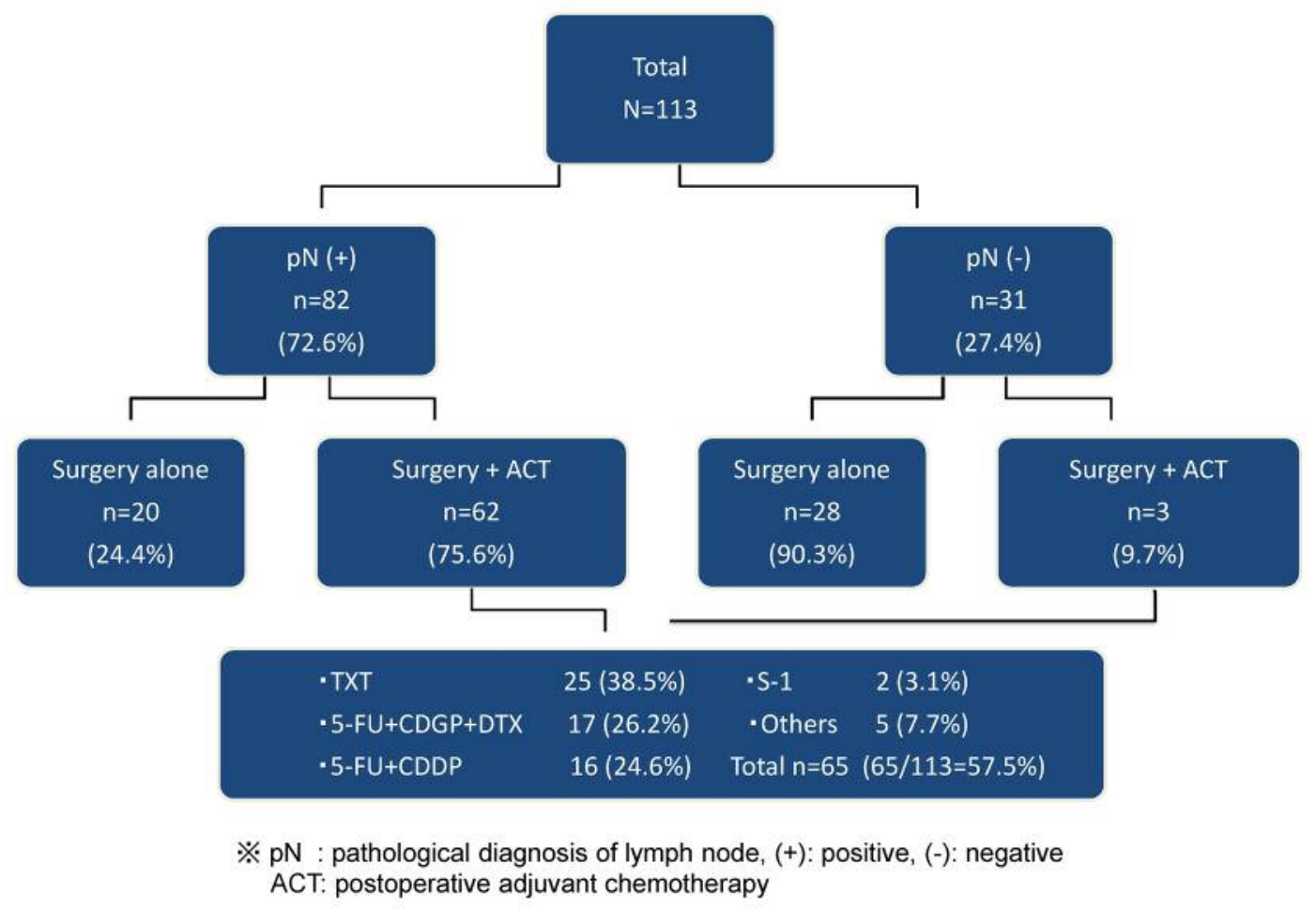

Figure 1. Details of treatment of the 113 patients included in the study.

significant difference between the two groups with respect to postoperative complications or treatment-related toxicities (10). However, one large randomized study failed to confirm a survival benefit with preoperative chemotherapy (12). Additionally, Matsuda et al., have reported that no significant difference in OS was observed between neoadjuvant chemotherapy (NAC) and upfront surgery in clinical stage III ESCC patients (13). Standard chemotherapy and treatment regimens applied in various institutions change over time. Postoperative chemotherapy has been performed previously at our Institution. In the current study, the results of postoperative chemotherapy treatment are reported.

\section{Patients and Methods}

We reviewed 113 consecutive patients with esophageal carcinoma who underwent esophagectomy at Gunma University Hospital, Gunma, Japan, between January 2004 and December 2013. Patients were enrolled in this study according to the following eligibility criteria: 1) diagnosis of thoracic esophageal cancer, clinical stage II or stage III by preoperative medical imaging examinations. 2) receipt of radical esophagectomy, confirming R0 resection (no residual disease at the resection margins), with two- or three-field lymphadenectomy. 3) pathologically-confirmed squamous cell carcinoma, adenocarcinoma, sarcomatoid carcinoma, or adenosquamous carcinoma. 4) No evidence of distant metastasis following preoperative medical imaging examinations, including endoscopic ultrasonography (EUS), computed tomography (CT) from cervix to abdomen, and 18-fluorodeoxyglucose positron emission tomography/computerized tomography (FDG-PET/CT). 5) Patient had not received treatment with neoadjuvant therapy, including chemotherapy, radiotherapy, or chemoradiotherapy. All pathological staging of patients' tumors was based on the seventh edition of the UICC TNM staging (14).

Surgery. All patients underwent radical esophagectomy with threefield lymphadenectomy (McKeown) or two-field lymphadenectomy (Ivor-Lewis). Muscle-sparing thoracotomy for esophagectomy in esophageal cancer patients was performed as a less-invasive procedure. As compared with normal open esophagectomy, this method is minimally invasive. Gastric tubes, the jejunum, and the colon were used to reconstruct the digestive tract after esophagectomy. Additionally, the anastomotic mode was normally performed, using stapled anastomosis. Posterior mediastinal routes were mostly chosen in our institution, as compared with retrosternal and antethoracic routes. The retrosternal route was chosen to avoid interference with alimentary tract function by the recurrence of a mediastinal tumor. In addition, postoperative irradiation can be performed on the tumor bed to lessen the chances of tumor recurrence without damaging the conduit. 


\section{Reasons for exclusion from adjuvant chemotherapy}

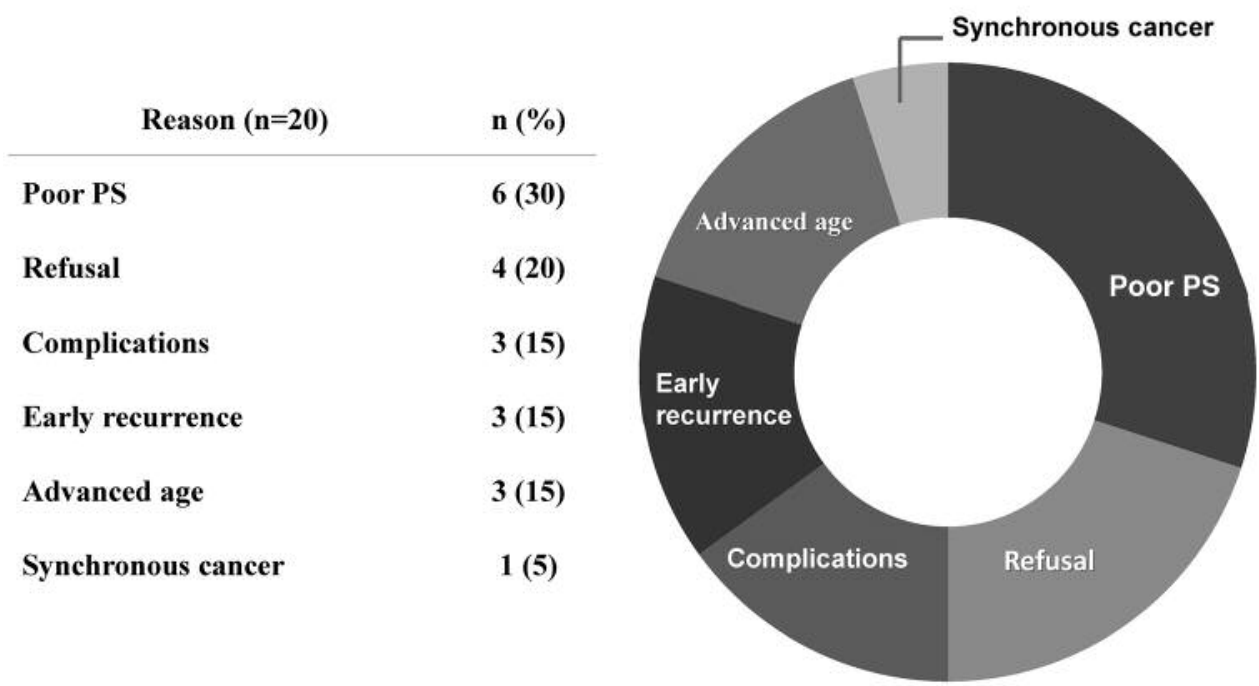

Figure 2. Reasons for excluding 20 patients in the $\mathrm{pN}(+)$ group from receiving adjuvant chemotherapy treatment.

Treatment with chemotherapy. In the current study, a total of 65 patients $(57.5 \%)$ received postoperative adjuvant chemotherapy at our institution. Among these patients, 25 of $65(38.5 \%)$ received docetaxel single-agent chemotherapy (at a recorded dosage of $35 \mathrm{mg} / \mathrm{m}^{2}$ ), and 17 of $65(26.2 \%)$ received a DNF (docetaxel, nedaplatin, and 5fluorouracil) chemotherapy regimen every 28 days. Docetaxel was infused intravenously on day 1 at a dosage of $60 \mathrm{mg} / \mathrm{m}^{2}$, nedaplatin was infused intravenously on day 1 at a dosage of $70 \mathrm{mg} / \mathrm{m}^{2}$, and 5FU was continually infused intravenously from day 1 to day 5 at a dosage of $700 \mathrm{mg} / \mathrm{m}^{2}$. A regimen of 5 -FU and cisplatin (FP) was performed in $24.6 \%$ (16 of 65 ) of patients every 28 days. Cisplatin was infused intravenously on day 1 at a dosage of $80 \mathrm{mg} / \mathrm{m}^{2}$, and 5FU was continually infused intravenously from day 1 to day 5 at a dosage of $800 \mathrm{mg} / \mathrm{m}^{2}$. Only 2 of 65 patients $(3.1 \%)$ received $\mathrm{S}-1$ single-agent chemotherapy. The remaining $7.7 \%$ (5 of 65) patients received other regimens. Chemotherapy regimens changed over time. The FP regimen, described above, has been performed in recent years.

Follow-up and toxicity. Patients were required to return for followup approximately every 3 months after surgery for 2 years, every 6 months for the next 3 years, and yearly thereafter. Recurrences, including regional lymph node or primary tumor relapses and distant metastases, were detected by endoscopy with or without biopsy, computed tomography, and, in recent years, FDG-PET/CT Toxicity was evaluated after each cycle of chemotherapy and was classified according to the common terminology criteria for adverse events (CTCAE).

Statistical analyses. Correlations of recurrence and clinicopathological factors between treatment groups were assessed by the $\chi^{2}$ test or Fisher's exact test. The Kaplan-Meier method was used to compare cancer-specific survival (CSS) and overall survival (OS) between treatment groups. Also, log-rank tests were used to test significance. A probability $(p)$ value of $<0.05$ was considered statistically significant.

\section{Results}

Patients and details of each treatment group. A total of 113 patients were included in the current retrospective investigation (Figure 1). Of these patients, 31 had pathologically confirmed no lymph node metastases $\mathrm{pN}(-)$, and 82 had pathologically confirmed positive lymph node metastases $\mathrm{pN}(+)$. Three patients in the $\mathrm{pN}(-)$ group received adjuvant chemotherapy after surgery because they were diagnosed as having significant risk factors, and 28 patients in the $\mathrm{pN}(-)$ group underwent treatment with surgery alone. Additionally, 62 patients in the $\mathrm{pN}(+)$ group received adjuvant chemotherapy. However, 20 patients in the $\mathrm{pN}(+)$ group did not receive adjuvant treatment due to several reasons presented in Figure 2. Thirty percent of all excluded patients did not undergo postoperative chemotherapy because of their insufficient performance status (PS), although positive lymph nodes were diagnosed pathologically. Moreover, 20 percent of these patients refused postoperative chemotherapy for various reasons.

Efficiency of adjuvant chemotherapy and the recurrence pattern in patients with pathologically positive lymph nodes. The CSSs of patients with $\mathrm{pN}(+)$ in the adjuvant group and the surgery-alone group were $59.0 \%$ and $43.1 \%$, respectively (Figure 3A). The adjuvant group had a tendency of good survival as compared with CSS. 
a

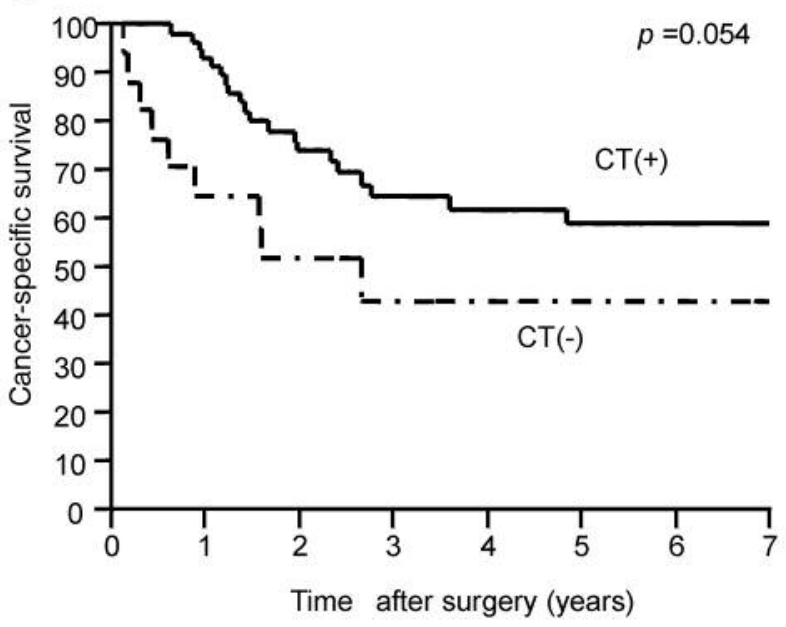

b

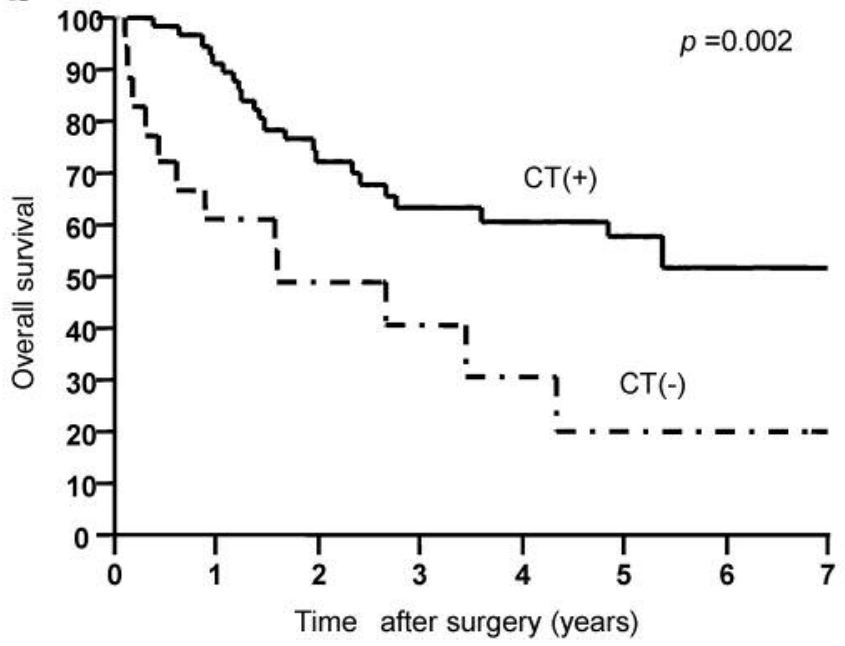

Figure 3. Postoperative survival rates. A. Cancer-specific postoperative survival rates in patients with positive lymph nodes. Patients in the postoperative adjuvant group tended to exhibit more favorable prognoses compared to the surgery-alone group (five-year survival rates: adjuvant group, 59.0\%; surgery-alone group, 43.1\%). B. Overall postoperative survival (OS) rates in patients with positive lymph nodes. Patients in the postoperative adjuvant group had significantly more favorable prognoses compared to those in the surgery-alone group (five-year survival rates: adjuvant group, 42.0\%; surgery-alone group, 20.4\%).

The 5-year OS of the adjuvant group and the surgeryalone group in patients with $\mathrm{pN}(+)$ were $42.0 \%$ and $20.4 \%$, respectively (Figure 3B). Adjuvant chemotherapy brought a significantly superior OS $(p=0.002)$, although there was no significant difference in CSS $(p=0.054)$. With regard to cases of recurrence in the adjuvant group of $\mathrm{p}(\mathrm{N}+)$, there was a significant correlation between recurrence and depth of invasion ( $\mathrm{pT})(p=0.003)$, number of lymph node metastases $(p=0.048)$, and venous invasion $(p<0.001)$ (Table I). The average number of lymph node metastases in recurrent cases was $5.93 \pm 0.9($ mean \pm SEM), and $3.35 \pm 0.9($ mean \pm SEM $)$ in non-recurrent cases. The median number of lymph node metastases was 2 (range $=1-16$ ) in non-recurrent cases and 4 (range $=1-32)$ in recurrent cases.

Risk factors of recurrence in the surgery-alone group without metastatic lymph nodes. With regard to recurrent cases in the surgery-alone group of $\mathrm{p}(\mathrm{N}-), 7$ cases $(25 \%)$ relapsed and showed lymph node metastases, distant metastases, and mixed metastases. Three cases with lymph node metastasis relapsed and presented with mediastinal lymph node metastasis, and one case showed simultaneous abdominal lymph node recurrence. Table II shows a comparison of characteristics of recurrent and non-recurrent cases in the surgery-alone group of $\mathrm{p}(\mathrm{N}-)$. With regard to recurrent cases, all (7 cases) showed lymphatic invasion, and six cases $(86 \%)$ showed venous invasion. Moreover, there were no welldifferentiated carcinomas in recurrent cases.

\section{Discussion}

Surgical resection has been the main treatment option for the management of esophageal cancer. Despite advances in surgical methodologies, long-term survival after surgery alone for advanced esophageal cancer remains poor. The implementation of perioperative chemotherapy has improved survival rates. The JCOG9204 clinical trial has demonstrated the utility of adjuvant chemotherapy in the subgroup of patients with positive lymph nodes as compared with the surgery alone group (5). As a result, preoperative chemotherapy is recommended for clinical stage II/III esophageal cancer patients (10) because the OS in the JCOG9907 clinical trial was significantly higher as compared with the outcome of the JCOG9204 trial. The theoretical advantages of adding chemotherapy to esophageal cancer treatment include potential tumor downstaging prior to surgery as well as the targeting of micrometastases, thus decreasing the risk of distant metastasis. On the other hand, potential disadvantages include the morbidity and mortality associated with toxicity, disease progression with the selection of drug-resistant tumor clones, and the delay of definitive surgical treatment (15). With regard to the survival benefit of postoperative adjuvant chemotherapy, previous reports (5-8) have shown that adjuvant chemotherapy improves disease-free survival; however, these reports did not result in significant differences in OS as compared with surgery alone. Lyu et al. reported that postoperative taxane- 
Table I. Correlation recurrence cases and clinicopathological factors in postoperative adjuvant group of $\mathrm{pN}(+)$.

\begin{tabular}{|c|c|c|c|}
\hline & $\begin{array}{l}\text { No recurrence } \\
\quad(n=31)\end{array}$ & $\begin{array}{l}\text { Recurrence } \\
\quad(\mathrm{n}=31)\end{array}$ & $p$-Value \\
\hline Age & $63.4 \pm 1.5$ & $63.8 \pm 1.5$ & 0.85 \\
\hline \multicolumn{4}{|l|}{ Gender } \\
\hline M & 28 & 27 & \multirow[t]{2}{*}{0.69} \\
\hline $\mathrm{F}$ & 3 & 4 & \\
\hline \multicolumn{4}{|l|}{ Location } \\
\hline Ut & 3 & 2 & \multirow[t]{3}{*}{0.83} \\
\hline $\mathrm{Mt}$ & 13 & 12 & \\
\hline $\mathrm{Lt}$ & 15 & 17 & \\
\hline \multicolumn{4}{|l|}{ pT } \\
\hline 1 & 13 & 4 & \multirow[t]{4}{*}{0.003} \\
\hline 2 & 8 & 4 & \\
\hline 3 & 10 & 20 & \\
\hline 4 & 0 & 3 & \\
\hline Number of LN dissection & $75.5 \pm 4.2$ & $74.5 \pm 4.2$ & 0.86 \\
\hline Number of LN metastasis & $3.35 \pm 0.9$ & $5.93 \pm 0.9$ & 0.048 \\
\hline \multicolumn{4}{|l|}{ Histology } \\
\hline Well SCC & 5 & 6 & \multirow[t]{4}{*}{0.78} \\
\hline Mod SCC & 15 & 14 & \\
\hline Poor SCC & 9 & 7 & \\
\hline Others & 2 & 4 & \\
\hline \multicolumn{4}{|l|}{ ly } \\
\hline- & 1 & 1 & \multirow[t]{2}{*}{1} \\
\hline+ & 30 & 30 & \\
\hline $\mathrm{v}-$ & 11 & 1 & $<0.001$ \\
\hline+ & 20 & 30 & \\
\hline
\end{tabular}

based adjuvant chemotherapy improved the OS of patients with lymph node-positive thoracic esophageal squamous cell carcinoma as compared with surgery alone (16). Our data also showed that postoperative adjuvant chemotherapy improved OS. This result is important for postoperative adjuvant chemotherapy for esophageal cancer; however, further accumulation of cases is necessary because our study does not have a sufficient number of cases and chemotherapy regimens were changing over time. Also, the baseline characteristics were not well matched between the groups because of the insufficient number of cases.

In recurrent cases in lymph node-positive members of the adjuvant-chemotherapy group, there was a significant correlation between recurrence and the depth of invasion, number of lymph node metastases, and venous invasion. Our data show that these are important recurrence factors for the lymph node-positive members of the group given postoperative adjuvant chemotherapy. Therefore, patients with these recurrence factors need a more powerful regimen of adjuvant chemotherapy. We have previously reported the usefulness of combination chemotherapy of docetaxel, nedaplatin, and 5-fluorouracil for advanced esophageal cancer (17). Triplet chemotherapy regimens, including DCF,
Table II. Correlation recurrence cases and clinicopathological factors in surgery alone group of $\mathrm{pN}(-)$.

\begin{tabular}{|c|c|c|c|}
\hline & $\begin{array}{l}\text { No recurrence } \\
\quad(n=21)\end{array}$ & $\begin{array}{l}\text { Recurrence } \\
\quad(n=7)\end{array}$ & $p$-Value \\
\hline Age & $71.3 \pm 7.0$ & $65.4 \pm 10.8$ & 0.21 \\
\hline \multicolumn{4}{|l|}{ Gender } \\
\hline M & 18 & 7 & \multirow[t]{2}{*}{0.28} \\
\hline $\mathrm{F}$ & 3 & 0 & \\
\hline \multicolumn{4}{|l|}{ Lesion } \\
\hline Ut & 2 & 0 & \multirow[t]{3}{*}{0.32} \\
\hline Mt & 10 & 3 & \\
\hline $\mathrm{Lt}$ & 9 & 4 & \\
\hline \multicolumn{4}{|l|}{ pT } \\
\hline 1 & 7 & 0 & \multirow[t]{3}{*}{0.09} \\
\hline 2 & 3 & 2 & \\
\hline 3 & 11 & 5 & \\
\hline Number of LN dissection & $67.6 \pm 31.2$ & $73.6 \pm 24.6$ & 0.65 \\
\hline \multicolumn{4}{|l|}{ Histology } \\
\hline Well SCC & $7(33.3)$ & 0 & \multirow[t]{4}{*}{0.18} \\
\hline Mod SCC & $10(47.6)$ & $4(57)$ & \\
\hline Poor SCC & $2(9.5)$ & $2(29)$ & \\
\hline Basaloid & $2(9.5)$ & $1(14)$ & \\
\hline \multicolumn{4}{|l|}{ ly } \\
\hline- & $5(23.8)$ & 0 & \multirow[t]{2}{*}{0.14} \\
\hline+ & $16(76.2)$ & $7(100)$ & \\
\hline \multicolumn{4}{|c|}{$\mathrm{v}$} \\
\hline- & $8(38.1)$ & $1(14)$ & \multirow[t]{2}{*}{0.21} \\
\hline+ & $13(61.9)$ & $6(86)$ & \\
\hline \multicolumn{4}{|l|}{$\operatorname{Inf}$} \\
\hline$\alpha$ & $2(9.5)$ & 0 & \multirow[t]{3}{*}{0.24} \\
\hline$\beta$ & $18(85.7)$ & $6(86)$ & \\
\hline$\gamma$ & $1(4.8)$ & $1(14)$ & \\
\hline
\end{tabular}

may be among the most powerful postoperative chemotherapies in the near future. The addition of radiotherapy (RT) might also be appropriate for such patients. Recently, several reports have shown that postoperative chemoradiotherapy (CRT) for patients with positive lymph nodes improves OS as compared with surgery alone $(18,19)$. Chen et al., reported that in node-positive patients, postoperative CRT is significantly more effective than RT alone in increasing overall survival and decreasing rates of distant metastasis, mixed metastasis, and overall recurrence for thoracic esophageal cancer patients (18). Hsu et al., reported that the median OS and median DFS were significantly higher in the CRT group than in the surgeryalone group (19). However, there is insufficient evidence for adjuvant CRT at this time. In the future, randomized control studies comparing adjuvant chemotherapy to adjuvant chemoradiotherapy will be needed to demonstrate their usefulness. In recurrent cases of the surgery-alone group without positive lymph nodes, the not well-differentiated type and lymphatic or venous invasion were important risk 
factors for recurrence. Therefore, patients with these risk factors might be new targets for postoperative adjuvant chemotherapy, even with negative lymph nodes. Further development of effective regimens, including molecular targeted therapies, will improve survival in esophageal cancer patients.

\section{Conflicts of Interest}

The Authors state that they have no conflict of interest and have received no payment in the preparation of this manuscript.

\section{References}

1 Daly JM, Karnell LH and Menck HR: National Cancer Data Base report on esophageal carcinoma. Cancer 78: 1820-1828, 1996.

2 Wobst A, Audisio RA, Colleoni $\mathrm{M}$ and Geraghty JG: Oesophageal cancer treatment: studies, strategies and facts. Ann Oncol 9: 951-962, 1998.

3 Zhang HL, Chen LQ, Liu RL, Shi YT, He M, Meng XL, Bai SX and Ping YM: The number of lymph node metastases influences survival and International Union Against Cancer tumor-nodemetastasis classification for esophageal squamous cell carcinoma. Dis Esophagus 23: 53-58, 2010.

4 Lin CS, Chang SC, Wei YH, Chou TY, Wu YC, Lin HC, Wang LS and Hsu WH: Prognostic variables in thoracic esophageal squamous cell carcinoma. Ann Thorac Surg 87: 1056-1065, 2009.

5 Ando N, Iizuka T, Ide H, Ishida K, Shinoda M, Nishimaki T, Takiyama W, Watanabe H, Isono K, Aoyama N, Makuuchi H, Tanaka O, Yamana H, Ikeuchi S, Kabuto T, Nagai K, Shimada Y, Kinjo Y and Fukuda H; Japan Clinical Oncology Group: Japan Clinical Oncology Group: Surgery plus chemotherapy compared with surgery alone for localized squamous cell carcinoma of the thoracic esophagus: a Japan Clinical Oncology Group Study--JCOG9204. J Clin Oncol 21: 4592-4596, 2003.

6 Lee J, Lee KE, Im YH, Kang WK, Park K, Kim K and Shim YM: Adjuvant chemotherapy with 5-fluorouracil and cisplatin in lymph node-positive thoracic esophageal squamous cell carcinoma. Ann Thorac Surg 80: 1170-1175, 2005.

7 Zhang SS, Yang H, Xie X, Luo KJ, Wen J, Bella AE, Hu Y, Yang $\mathrm{F}$ and $\mathrm{Fu} \mathrm{JH}$ : Adjuvant chemotherapy versus surgery alone for esophageal squamous cell carcinoma: a meta-analysis of randomized controlled trials and nonrandomized studies. Dis Esophagus 27: 574-584, 2014.

8 Qin RQ, Wen YS, Wang WP, Xi KX, Yu XY and Zhang LJ: The role of postoperative adjuvant chemotherapy for lymph nodepositive esophageal squamous cell carcinoma: a propensity score matching analysis. Med Oncol 33: 31, 2016.

9 Medical Research Council Oesophageal Cancer Working Group. Surgical resection with or without preoperative chemotherapy in oesophageal cancer: a randomized controlled trial. Lancet 18 : 1727-1733, 2002.
10 Ando N, Kato H, Igaki H, Shinoda M, Ozawa S, Shimizu H, Nakamura T, Yabusaki H, Aoyama N, Kurita A, Ikeda K, Kanda $\mathrm{T}$, Tsujinaka T, Nakamura $\mathrm{K}$ and Fukuda $\mathrm{H}$ : A randomized trial comparing postoperative adjuvant chemotherapy with cisplatin and 5-fluorouracil versus preoperative chemotherapy for localized advanced squamous cell carcinoma of the thoracic esophagus (JCOG9907). Ann Surg Oncol 19: 68-74, 2012.

11 Ychou M, Boige V, Pignon JP, Conroy T, Bouché O, Lebreton G, Ducourtieux M, Bedenne L, Fabre JM, Saint-Aubert B, Genève $\mathrm{J}$, Lasser $\mathrm{P}$ and Rougier P: Perioperative chemotherapy compared with surgery alone for resectable gastroesophageal adenocarcinoma: an FNCLCC and FFCD multicenter phase III trial. J Clin Oncol 1: 1715-1721, 2011.

12 Kelsen DP, Ginsberg R, Pajak TF, Sheahan DG, Gunderson L, Mortimer J, Estes N, Haller DG, Ajani J, Kocha W, Minsky BD and Roth JA: Chemotherapy followed by surgery compared with surgery alone for localized esophageal cancer. N Engl J Med 31: 1979-1984, 1998.

13 Matsuda S, Tsubosa Y, Sato H, Takebayashi K, Kawamorita K, Mori K, Niihara M, Tsushima T, Yokota T, Onozawa Y, Yasui H, Takeuchi $\mathrm{H}$ and Kitagawa Y: Comparison of neoadjuvant chemotherapy versus upfront surgery with or without chemotherapy for patients with clinical stage III esophageal squamous cell carcinoma. Dis Esophagus 1: 1-8, 2017.

14 Leslie H, Sobin and Mary K: Gospodarowicz, Christian Wittekind: TNM Classification of Malignant Tumours, 7th Edition. 2009.

15 Kato $\mathrm{H}$ and Nakajima M: Treatments for esophageal cancer: a review. Gen Thorac Cardiovasc Surg 61: 330-335, 2013.

16 Lyu X, Huang J, Mao Y, Liu Y, Feng Q, Shao K, Gao S, Jiang $\mathrm{Y}$, Wang $\mathrm{J}$ and $\mathrm{He} \mathrm{J}$ : Adjuvant chemotherapy after esophagectomy: is there a role in the treatment of the lymph node positive thoracic esophageal squamous cell carcinoma? J Surg Oncol 110: 864-868, 2014.

17 Miyazaki T, Ojima H, Fukuchi M, Sakai M, Sohda M, Tanaka N, Suzuki S, Ieta K, Saito K, Sano A, Yokobori T, Inose T, Nakajima M, Kato $\mathrm{H}$ and Kuwano H: Phase II study of docetaxel, nedaplatin, and 5-Fluorouracil combined chemotherapy for advanced esophageal cancer. Ann Surg Oncol 22: 3653-3658, 2015.

18 Chen J, Pan J, Liu J, Li J, Zhu K, Zheng X, Chen M, Chen M and Liao Z: Postoperative radiation therapy with or without concurrent chemotherapy for node-positive thoracic esophageal squamous cell carcinoma. Int J Radiat Oncol Biol Phys 15: 671-677, 2013.

19 Hsu PK, Huang CS, Wang BY, Wu YC and Hsu WH: Survival benefits of postoperative chemoradiation for lymph nodepositive esophageal squamous cell carcinoma Ann Thorac Surg 97: 1734-1741, 2014. 